\title{
A Importância do Jornal da LIRNNE
}

Aproveito este espaço do nosso maior instrumento de comunicação para apontar evidências confirmando que o nascimento de um filho faz somar e não dividir. Com esse pensamento nasceu o Jornal da Liga dos Reumatologistas do Norte/Nordeste (JL), que estará lançando o seu segundo número em breve, contendo três artigos originais, dois artigos de revisão de literatura e dois relatos de casos. Esse periódico foi idealizado pelos conterrâneos do Norte/ Nordeste como uma forma de estímulo para que fossem divulgadas experiências científicas muitas vezes esquecidas em prateleiras de bibliotecas sob a forma de dissertações e teses jamais lidas. Adicionalmente, tornava-se dificil de se acreditar que nas terras de Castro Alves, Gonçalves Dias, Graciliano Ramos, José de Alencar, Jorge Amado, Manuel Bandeira, Nelson Rodrigues, sem falar de Carlinhos Brown e Caetano Veloso, dentre muitos outros, não houvesse inspiração científica para a criação de uma revista regional.

Recebemos críticas até de respeitáveis colegas da LIRNNE de que o JL enfraqueceria a Revista Brasileira de Reumatologia (RBR), na medida em que esta receberia menos artigos originais para a sua publicação, critério da maior importância para se almejar uma indexação em bases de dados como o MEDLINE ou o ISI.

Com essa preocupação em mente, fez-se um estudo objetivando identificar o destino dos trabalhos originados em alguns centros de reumatologia do Brasil. Como material e métodos foram escolhidos doze nomes da reumatologia brasileira e foram pesquisadas as suas publicações que apareceram no MEDLINE ou na RBR nos últimos cinco anos. Destes, três foram da cidade de São Paulo, dois do "Nordeste", dois de Campinas, dois do Rio Grande Sul, um do Rio de Janeiro, um de Ribeirão Preto e um de Goiânia. Como resultado observou-se que 148 trabalhos foram publicados por esses autores em revistas indexadas no MEDLINE, enquanto que apenas 97 foram publicados na RBR. A Tabela 1 mostra a distribuição dos trabalhos conforme os centros estudados. Pode-se discutir então a razão para a existência de apenas poucos trabalhos sendo submetidos para publicação na RBR: as evidências aqui apresentadas demonstram que os reumatologistas do Brasil

TABELA 1

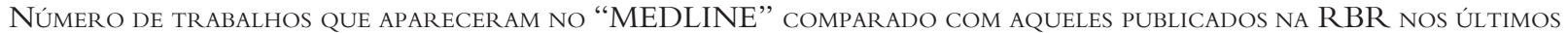
CINCO ANOS, ORIUNDOS DE 12 DIFERENTES CENTROS DE REUMATOLOGIA DO BRASIL

\begin{tabular}{|c|c|c|c|c|}
\hline $\begin{array}{l}\text { Centro (número de } \\
\text { reumatologistas incluídos) }\end{array}$ & Reumatologista $\mathrm{A}$ & Reumatologista B & Reumatologista C & Total de publicações \\
\hline São Paulo (3) & $\begin{array}{l}\text { MEDLINE: } 15 \\
\text { RBR: } 9\end{array}$ & $\begin{array}{l}\text { MEDLINE: } 14 \\
\text { RBR: } 5\end{array}$ & $\begin{array}{l}\text { MEDLINE: } 9 \\
\text { RBR: } 13\end{array}$ & $\begin{array}{l}\text { MEDLINE: } 38 \\
\text { RBR: } 27\end{array}$ \\
\hline “Nordeste" (2) & $\begin{array}{l}\text { MEDLINE: } 15 \\
\text { RBR: } 6\end{array}$ & $\begin{array}{l}\text { MEDLINE: } 9 \\
\text { RBR: } 8\end{array}$ & & $\begin{array}{l}\text { MEDLINE: } 24 \\
\text { RBR: } 14\end{array}$ \\
\hline Campinas (2) & $\begin{array}{l}\text { MEDLINE: } 18 \\
\text { RBR: } 16\end{array}$ & $\begin{array}{l}\text { MEDLINE: } 13 \\
\text { RBR: } 13\end{array}$ & & $\begin{array}{l}\text { MEDLINE: } 31 \\
\text { RBR: } 29\end{array}$ \\
\hline Rio Grande do Sul (2) & $\begin{array}{l}\text { MEDLINE: } 7 \\
\text { RBR: } 9\end{array}$ & $\begin{array}{l}\text { MEDLINE: } 4 \\
\text { RBR: } 8\end{array}$ & & $\begin{array}{l}\text { MEDLINE: } 9 \\
\text { RBR: } 17\end{array}$ \\
\hline Rio de Janeiro (1) & $\begin{array}{l}\text { MEDLINE: } 9 \\
\text { RBR: } 5\end{array}$ & & & $\begin{array}{l}\text { MEDLINE: } 9 \\
\text { RBR: } 5\end{array}$ \\
\hline Ribeirão Preto (1) & $\begin{array}{l}\text { MEDLINE: } 36 \\
\text { RBR: } 3\end{array}$ & & & $\begin{array}{l}\text { MEDLINE: } 36 \\
\text { RBR: } 3\end{array}$ \\
\hline Goiânia (1) & $\begin{array}{l}\text { MEDLINE: } 1 \\
\text { RBR: } 2\end{array}$ & & & $\begin{array}{l}\text { MEDLINE: } 1 \\
\text { RBR: } 2\end{array}$ \\
\hline Total de publicações & & & & $\begin{array}{l}\text { MEDLINE: } 148 \\
\text { RBR: } 97\end{array}$ \\
\hline
\end{tabular}


preferem ter seus trabalhos enviados para uma revista indexada no MEDLINE a vê-los publicados na RBR. Ora, se um trabalho publicado na RBR não impede que este mesmo manuscrito seja publicado em uma revista indexada no MEDLINE, então como o JL, periódico sem qualquer indexação, poderia "dividir" a RBR? Deve ser também lembrada a existência de outros periódicos de veiculação nacional na área de reumatologia, desenvolvidos por sociedades estaduais e até mesmo por serviços específicos, que têm publicado regularmente artigos científicos e que não parecem representar ameaça para a RBR. Em conclusão, os achados do presente "estudo" parecem sugerir que: a) estamos dando maior ênfase à "exportação" do nosso melhor produto científico;

b) há uma grande distorção na interpretação de que o JL veio para dividir, como sugerido por alguns. Pelo contrário, entende-se que com o salutar hábito de publicar manuscritos, poder-se-á submeter trabalhos de melhor qualidade à RBR e assim a reumatologia brasileira tenderá a crescer de maneira mais uniforme.

Mittermayer B. Santiago

Editor do Jornal da Liga dos Reumatologistas do Norte/Nordeste (JL) E-mail: mitter@svn.com.br 